\section{Bócio Multinodular Tóxico: Aspectos Clinicos e Conduta}

artigo original

\author{
Marcos A. Tambascia
}

Disciplina de EndocrinologiaUNICAMP

Presidente do Departamento de Tireóide da SBEM
A PRESENÇA DE NÓdULOS TIROIDEANOS múltiplos, funcionando independentemente do controle da retro-alimentação pelo TSH hipofisário, é uma causa de tirotoxicose associada à hipertiroidismo. Estes nódulos são constituídos por células hiperfuncionantes, que apresentam propriedades de sintetizar e secretar os hormônios tiroideanos (1). Esta hiperprodução hormonal inibe a secreção de TSH, o que leva a uma supressão funcional do parênquima adjacente à área nodular. Ao exame cintilográfico realizado com iodo 131 ou $T c-99$ m revela captação exclusiva aos tecidos hiperfuncionantes, levando ao aspecto típico cintilográfico de vários nódulos hipercaptantes (nódulos "quentes") entremeado à nódulos năo concentrantes do radioisótopo (nódulos "frios"). A ocorrência de vários nódulos hiperconcentrantes do radioisótopo é menos freqüente do que a presença de apenas um nódulo. A característica funcional desta entidade é a autonomia nodular; assim, a realização de um teste de supressão (realização da cintilografia na vigência de doses fisiológicas de hormônio tiroideano) revelará uma supressão negativa e o estímulo eventual com TSH exógeno ou endógeno (durante o tratamento com drogas antitiroideanas) evidenciará que o tecido extranodular é capaz de ser estimulado. O estado clínico destes pacientes é variável, podendo ser encontrado indivíduos com tirotoxicose ou mesmo totalmente eutiroideanos (2), como na maioria dos casos. Quando a presença de folículos com capacidade de autonomia for em número suficiente para ocasionar aumento dos níveis séricos dos hormônios tiroideanos aparecerá a tirotoxicose. Com certa freqüência encontraremos pacientes con hipertiroidismo subclínico, que pode preceder a instalação de tirotoxicose.

Histologicamente estes nódulos se apresentam com características de hipercelularidade e sinais de hiperatividade. O parênquima nodular pode se caracterizar como um adenoma ou apenas uma hiperplasia glândular (3).

Funcionalmente estes nódulos se comportam como portadores de alterações intrínsecas que lhes confere autonomia. Um fator extratiroideano circulante, como ocorre na doença de Graves, é descartado pela presença de áreas autônomas e normais no mesmo tecido tiroideano e pela persistência destas anormalidades em cultura de tecido.

Recentemente, têm sido publicados na literatura especializada estudos que revelam mutações no receptor de TSH $(4,5)$ ou na subunidade alfa estimuladora da proteína ligadora guanina nucleotídeo $(6,7)$, ocasionando ativação do receptor ou seu efeito quando estimulado, mesmo sem a presençi do TSH.

O hipertiroidismo por bócio multinodular não é uma causa freqüente de tirotoxicose, prém em regiōes com baixa ioł́chllia passa a ser uma causa considerável 5 a 15\% dus casos em uma casuística no Reino Unido e Canadá (8,9).

O quadro clínico adrenérgico é mais brando do que o de pacientes
Recebido em $29 / 6 / 98$

Revisain en 29/7/98 Aceito em $29 / 7 / 98$ 
com doença de Graves, pois, incidindo de maneira mais insidiosa e em indivíduos mais idosos, levará a hipertiroidismo sublínico ou mais freqüentemente sinais e sintomas do excesso de tiroxina para o sistema cardio-vascular, como arritmias ou quadro de insuficiência cardíaca congestiva (2).

$\mathrm{O}$ encontro de TSH suprimido em indivíduos idosos, mesmo sem nódulo cervical palpável, indica a necessidade de estudo cintilográfico que poderá determinar a ocorrência de bócio multinodular hipercaptante. Como muitos destes nódulos secretam preferencialmente $\mathrm{T} 3$, esta dosagem também é necessária além da determinação de tiroxina livre e TSH (2). O teste de estímulo com TSH ou mesmo o teste de supressão podem complementar, porém não são essenciais para o diagnóstico. A punção aspirativa com agulha fina não trará informações adicionais embora sempre é necessária para se afastar a associação com carcinoma (10). O estudo ultrassonográfico deverá revelar a presença de nódulo sólido e hipervascularizado (11).

\section{CONDUTA}

Diferentemente dos pacientes com Doença de Graves, cuja evolução para a remissão pde ser obtida com o tratamento clínico, nos casos de bócio nodular ou multinodular tóxico a terapia deve ser a ablativa. Esta terapia pode ser realizada de 3 modos: cirurgia, radioioterapia ou através de injeção percutânea de etanol.

Se o paciente apresentar bócio multinodular, que, além de hiperfuncionante levando à quadro de tirotoxicose, também está levando à sintomas e sinais de compressão, a conduta mais indicada é a ressecção cirúrgica. A cirurgia geralmente não é complexa e levará a uma normalização do tecido adjacente que estava inibido. Como estes pacientes estão $\mathrm{cm}$ tirotoxicose é necessário a preparação prévia com anti-tiroideanos e agentes beta-adrenérgicos. $\mathrm{O}$ uso de iodo inorgânico por 7 a 10 dias antes da cirurgia também é aconselhável. O hipotiroidismo pós-operatório é raro (12).

O tratamento com radioiodo (I131) é eficaz tanto quanto a cirurgia. Como não existem aqui os riscos anestésico e cirúrgicos, alguns serviços consideram esta a melhor opção de terapia ablativa definitiva. No entanto como estes nódulos são resistentes à radioiodo, a dose a ser empregada é maior que a utilizada para o tratamento da Doença de Graves. Pacientes com nódulos grandes ou múltiplos necessitam de altas doses de I131, o que nos leva à preocupação do efeito da radiação no tecido extra-nodular. Embora passível de aumentar a ocorrência de carcino- ma de tiróide na área adjacente, este efeito não é encontrado na clínica e na literatura. A ocorrência de hipotiroidismo pós ablação actínica é considerável e varia muito nos estudos publicados (0 a 44\%) (13).

Como regra, geralmente os pacientes mais jovens e os com nódulos maiores são encaminhados à cirurgia e os mais idosos e com nódulos menores são indicados à terapia ablativa com radioiodo.

Se o paciente apresentar bócio multinodular, hipercaptante, porém sem quadro clínico de tirotoxicose e scm sinais compressivos, a melhor opção é a expectante, pois nem todos os casos irão evoluir para a toxicidade (14). Se o paciente for idoso e com nódulos maiores que $3 \mathrm{~cm}$ a probabilidade de tirotoxicose futura é maior, assim uma conduta com radioioterapia ou mesmo cirúrgica deve ser considerada.

A injeção percutânea de etanol é uma alternativa recentemente introduzida na prática clínica $(15,16)$. O procedimento, que não é complexo, consiste na injeção de volumes pequenos de etanol $(1$ a $10 \mathrm{ml}$ ) diretamente no centro do nódulo guiado por ecografia. Para a destruição dos nódulos são necessárias geralmente várias injeções. Como este procedimento é relativamente recente, o número de casos assim tratados é pequeno na literatura, no entanto a técnica parece ser inócua e efetiva. Dor local e mesmo paralisia e disfunções temporárias de cordas vocais são descritas.

Após a terapia ablativa estes pacientes devem ser avaliados periodicamente, no sentido de se diagnosticar um nódulo não hiperfuncionante que adquire autonomia e portanto recidiva do hipertiroidismo ou mesmo hipotirodismo tardio. Recomenda-se avaliações com TSH e níveis dos hormônios tiroideanos anualmente.

\section{REFERÊNCIAS}

1. Van Sande, $J$ et al. Pathogenesis of autonomous thyroid nodules: in vitro study of iodine and adenosine $3^{\prime} 5^{\prime}$ monophosphate metabolism. J Clin Endocrinol Metab $1988 ; 66: 570$.

2. Hamburger, Jl. Evolution of toxicity in solitary nontoxic autonomously funtioning thyroid nodules. J Clin Endocrinol Melab 1980;50:1089.

3. Croom, RD et al. Autonomously funtioning thyroid nodules in childhood and adolescence. Surgery 1987; 102:1101.

4. Parma $J$ et al. Somatic mutations in the thyrotropin receptor gene cause hyperfunctioning thyroid adenomas. Nature 1993;365:649

5. Porcellini, $A$ et al. Novel mutations of thyrotropin receptor gene in thyroid hyperfunctioning adenomas. J Clin Endocrinol Metab 1994;79:657.

6. Russo, D et al. Genetic alterations in thyroid hyperfunc- 
tioning adenomas. J Clin Endocrinol Metab 1995;80:1347.

7. Lyons, $J$ et al. Two $G$ protein oncogenes in human endocrine tumors. Science 1990;249:655.

8. Fogelman, I et al. The role of thyroid scanning in hyperthyroidism. Eur J Nucl Med 1986; 11:397.

9. Willians, 1 et al. Aetiology of hyperthyroidism in Canada and Wales. J Epidemiol Community Health 1983;37:245.

10. Walfish, $P G$ et al. Management implications from routine needle biopsy of hyperfunctioning thyroid nodules. Surgery 1985;98:1179.

11. Fobbe, $\mathrm{F}$ et al. Appearance of thyroid diseases using color-coded duplex sonography. Eur J Radiol 1989;9:29.

12. Kinser, JA et al. Nonimmunogenic hyperthyroidism: cumulative hypothyroidism incidence after radioiodine and surgical treatment. J Nucl Med 1989;30:1960.

13. Fontana, $\mathrm{B}$ et al. The incidence of hypothyroidism after radioactive iodine $\left({ }^{13}\right)$ ) therapy for autonomous hyper- functioning thyroid nodules evaluated by means of lifetable methods. J Nucl Med Allied Sci 1980;24:85

14. Burman, KD ef al. Clinical observations on the solitary autonomous thyroid nodules. Arch Intern Med $1974 ; 134: 915$.

15. Monzani, $\mathrm{F}$ et al. Percutaneous ethanol injection treatment of autonomous thyroid adenoma: hormonal and clinical evaluation. Clin Endocrinol 1992;36:491.

16. Martino, E et al. Percutaneous intranodular ethanol injection for treatment of autonomously funtioning thyroid nodules. Surgery 1992; $112: 1161$.

\section{Endereço para correspondência:}

Marcos A. Tambascia

Disciplina de Endocrinologia

Departamento de Clínica Médica

Universidade Estadual de Campinas-Unicamp

Cidade Universitátia ZEFERINO VAZ

13084 - 100 Campinas, SP 